\title{
A Systematic Literature Review on Image Information Needs and Behaviors
}

Hyerim Cho (Corresponding Author)

School of Information Science \& Learning Technologies, University of Missouri $303 \mathrm{~K}$ Townsend Hall, Columbia, MO 65211

Phone: 573-882-5981

hyerimcho@missouri.edu

\section{Minh Pham}

School of Information Science \& Learning Technologies, University of Missouri 303 Townsend Hall, Columbia, MO 65211 minhpham@mail.missouri.edu

\section{Katherine Leonard}

School of Information Science \& Learning Technologies, University of Missouri 303 Townsend Hall, Columbia, MO 65211 knln9c@mail.missouri.edu

\footnotetext{
Alex Urban

School of Information Science \& Learning Technologies, University of Missouri 303 Townsend Hall, Columbia, MO 65211 urbanac@mail.missouri.edu
} 


\begin{abstract}
Purpose - With ready access to search engines and social media platforms, the way people find image information has evolved and diversified in the past two decades. The purpose of this paper is to provide an overview of the literature on image information needs and behaviors.

Design/methodology/approach - Following an eight-step procedure for conducting systematic literature reviews, the paper presents an analysis of peer-reviewed work on image information needs and behaviors, with publications ranging from the years 1997 to 2019.

Findings - Application of the inclusion criteria led to 69 peer-reviewed works. These works were synthesized according to the following categories: research methods, users targeted, image types, identified needs, search behaviors, and search obstacles. The reviewed studies show that people seek and use images for multiple reasons, including entertainment, illustration, aesthetic appreciation, knowledge construction, engagement, inspiration, and social interactions. The reviewed studies also report that common strategies for image searches include keyword searches with short queries, browsing, specialization, and reformulation. Observed trends suggest common deployment of query analysis, survey questionnaires, and undergraduate participant pools to research image information needs and behavior.
\end{abstract}

Originality - At this point, after more than two decades of image information needs research, a holistic systematic review of the literature was long overdue. The way users find image information has evolved and diversified due to technological developments in image retrieval. By synthesizing this burgeoning field into specific foci, this systematic literature review provides a foundation for future empirical investigation. With this foundation set, the paper then pinpoints key research gaps to investigate, particularly the influence of user expertise, a need for more diverse population samples, a dearth of qualitative data, new search features, and information and visual literacies instruction.

Keywords - Systematic Literature Review (SLR); Image Information Needs; Image Information Seeking Behavior; Images; Visual Information

\title{
Introduction
}

It has been over two decades since image information studies began to flourish. Once a relatively new subject within information science, images are now a crucial part of everyday media consumption. Whether it is images in a news article or a meme from Instagram, we are exposed to (and actively use) several images every day.

Social media platforms have played an important role in shifting the image search and use paradigm. In addition to utilizing conventional image search features of search engines, people can now use photo-sharing platforms such as Instagram, Flickr, and Tumblr as well image crowdsourcing services (Rampton, 2015) like Scoopshot to hire their own personal photographer to satisfy their image needs (See Figure 1). Image search strategies have changed, as well; from majorly relying on text-based search (Choi \& Hsieh-Yee, 2010; Hollink et al., 
2011), users now enjoy additional features such as voice-activated searches or reverse image searches (See Figure 2).

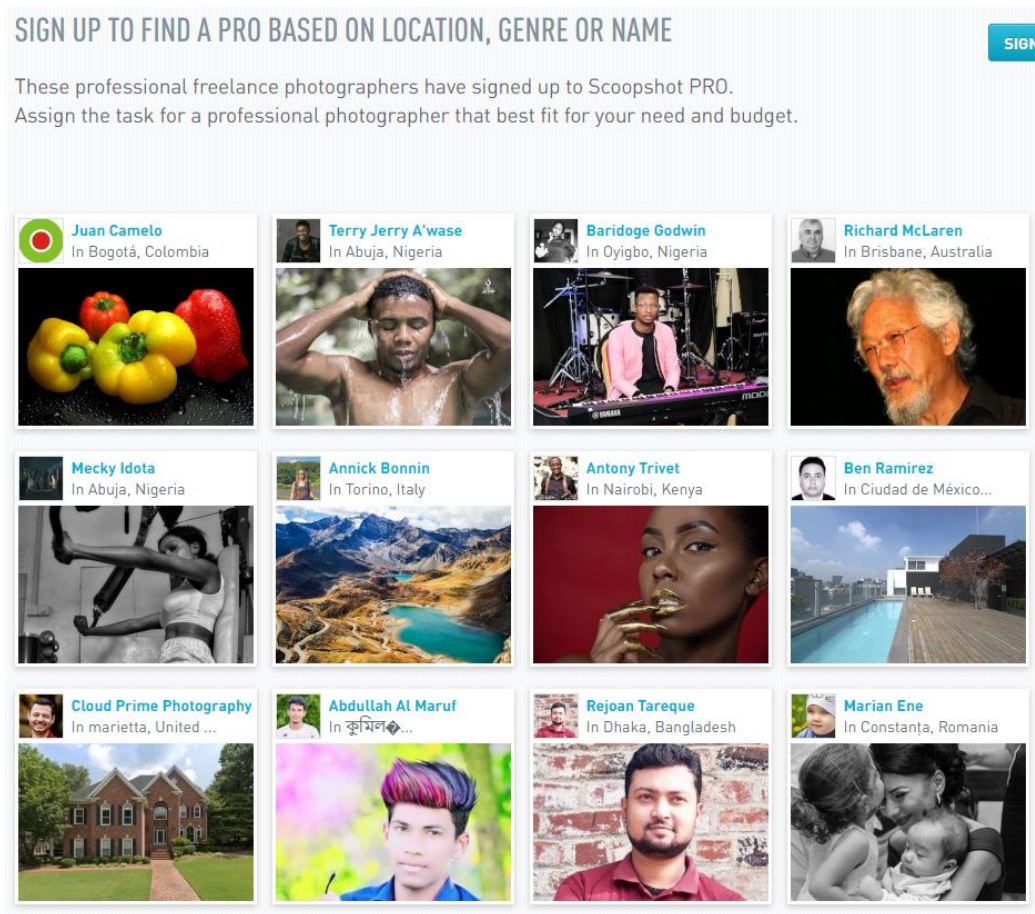

Figure 1: Scoopshot (image crowdsourcing service) homepage
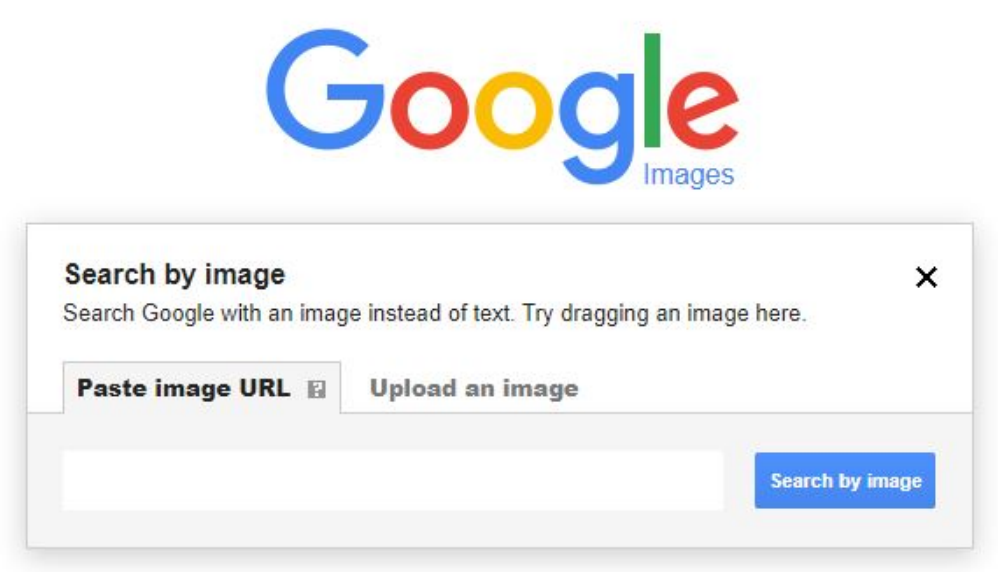

Figure 2: Google reverse image search

Existing image information needs studies have provided a good understanding of what image users (both general and professional) are looking for (e.g., Beaudoin, 2005; Chung \& Yoon, 2011; Cunningham et al., 2004). However, the way people find image information seems to have evolved and diversified in the past decade. This led us to ask: What is there to learn about image information users and their needs in the existing literature, and what needs to be studied further?

To address these questions, we conducted a systematic literature review of existing image information needs and behavior studies, focusing on these supporting research questions: 
RQ1. What have we learned so far about image information needs and behaviors?

RQ2. What are the identified research gaps in existing image information needs and behavior studies?

After more than two decades since image information needs studies began, a holistic systematic review of the literature is long overdue. Scholars and practitioners will benefit from such a review to expand and develop theoretical knowledge in this field as well as to enhance image information users' search experiences.

\section{Methods}

This systematic literature review followed the guidelines suggested by Okoli and Schagram (2010). Their eight-step guide has been suggested for Information Systems research primarily due to the field's interdisciplinary nature. The eight steps of conducting a systematic literature review suggested by Okoli and Schagram (2010) are as follows (with our summary of each step in parentheses):

1. Purpose of the literature review (the reviewers identify the goals of the review)

2. Protocol and training (the reviewers agree on the detailed procedure to follow)

3. Searching for the literature (the reviewers explicitly describe the details of the search)

4. Practical screen (the reviewers determine what studies will be considered for review)

5. Quality appraisal (the reviewers establish criteria for judging which articles are of insufficient quality)

6. Data extraction (the reviewers systematically extract applicable information from each study)

7. Synthesis of studies analysis (which may be quantitative, qualitative, or both)

8. Writing the review (in sufficient detail)

\section{Databases and Search Terms}

Following these guidelines, we conducted our systematic review on image information needs and seeking behaviors by searching library and information science discipline databases provided by the University of Missouri library (Ellis Library), including: Library Literature and Information Science Full Text, ERIC, Education Full Text, Academic Search Premier, JSTOR, Google Scholar, Scopus, ScienceDirect Freedom Collection, and Web of Science Core Collection. Utilizing the subject terms (SU) provided by the Ellis Library's advanced search to ensure exhaustive search results, the following search terms/phrases were used:

- SU (Information needs OR Information seeking OR Information seeking behavior OR Information searching OR Information searching behavior) AND TX (image* OR photo*)

In addition to the advanced subject terms (SU) search, we applied search expanders that allowed us to find other potentially relevant sources by applying equivalent subjects, related words, and full-text search. Then, we used two filters to limit the results: peer-reviewed 
academic journals and conference materials, and subjects (image retrieval; information retrieval; content-based image retrieval; digital libraries; information storage \& retrieval; image retrieval systems; information-seeking behavior; information retrieval, information \& knowledge management). Initial data collection was conducted from November 2019, resulting in 31 articles. Using the same search phrases and strategies, another data collection was conducted in May 2020 to ensure that any newly added or published articles were included. This process yielded an additional four articles.

Even after two sets of searches conducted, some important authors and articles were missing from the dataset. For the third search, the authors reached out to the LIS reference librarian at the Ellis Library. Based on the reference librarian's recommendations, the third search was conducted differently from the previous searches. Due to many databases' missing subject heading information or index terms, some of the relevant articles could not be captured with the initial strategy. Therefore, for the round of search that happened in December 2020, we flipped the focus of the subject heading. Instead of looking at the information needs as the subject headings, we looked at the image/photo field as the subject. Also, we included "image retrieval" in this round of search. This search keyword was not used in the initial sets since this term tends to yield too many results on content-based image retrieval (CBIR) and techniques, which was not our scope. However, to expand the search results, the authors decided to include "image retrieval" as a search term this round based on the reference librarian's recommendations. Then we went through extensive browsing to filter out the articles that were not in the scope of this study. Also, we focused on finding articles in Education Full Text, ERIC, and Library Literature \& Information Science Full Text, which all had the same advanced search mechanisms. The following search string was used for this search:

- SU (Images OR Pictures OR Photos) AND TX (image retrieval OR information needs OR information seeking)

The third search was able to yield an additional 34 articles. Thus, in sum, 69 articles (35 from the first and second round of searches and 34 from the third round of search) were selected for review.

\section{Review Criteria \& Initial Results}

Once we completed the data collection, we first reviewed each article's title and abstract to remove any irrelevant search results (i.e., studies that were not related to users' image information needs or behavior-related) and duplicated items. Other than selecting only peerreviewed articles, no other quality control filter criterion was applied. For topicality of the articles, however, the following exclusion criteria was used:

1. Studies that focus on organizing and managing image information, without discussing users' needs or search

2. Studies that mainly discuss technological developments regarding Content-Based Image Retrieval (CBIR), without discussing users' needs or search

3. Other irrelevant topics, such as "body image" 
After cleaning the data, 69 peer-reviewed works were selected for analysis. The publication range for the selected articles was 1997 to 2019. With the collected dataset, we created a spreadsheet where we organized and reviewed different aspects of each article, including basic descriptive metadata elements (e.g., journal name and publication year) and subject descriptions (e.g., types of image information the authors investigated, user groups, and research methods used). To analyze the information from the collected dataset, one reviewer filled out data entries for the first half of the articles with her analysis, and the other reviewer did the same for the second half of the articles. Then, two reviewers exchanged their assigned articles and reviewed the previous reviewer's analysis for consistency and reliability. In the end, the third reviewer reviewed the overall analysis of the literature again. The three reviewers had bi-weekly discussions to comprehensively identify and analyze the common themes and trends in the literature, as well as the research gaps and limitations. This iterative process lasted from November 2019 to June 2020, and from December 2020 to February 2021.

\section{Findings}

The early sections of the Findings and Discussion answer RQ1: "What have we learned so far about image information needs and behaviors?" by focusing on 1) research methods used, 2) users targeted, 3) image types investigated, 4) identified image information needs, 5) image information search behaviors, and 6) image search obstacles. At the end of this section, we will have a separate discussion to address RQ2: "What are the identified research gaps in existing image information needs and behavior studies?"

\section{Research Methods Used}

Table 1 shows the research methods used in the existing image information needs and behavior studies. Among the 14 research methods identified in our review, survey questionnaires and interviews were the most frequently selected, followed by query analysis and task analysis. This echoes Matusiak's (2017) findings that surveys, questionnaires, and transaction logs are favored research strategies. Matusiak (2017) also noted the limited qualitative research on image seeking, searching, and use.

Query analysis and survey methods have advantages in investigating image information users' needs and behavior. As Choi and Rasmussen (2003) note, query analysis shows how the "users' concept of the meanings of image information change through the searching process" (p. 502). Moreover, it allows researchers to observe the subject/theme of each image that users search for, and how the search query evolves when the initial search was unsatisfactory. Survey methods, on the other hand, are useful for asking direct questions to users about their image needs, uses, and search experiences. For instance, Yoon (2011) used surveys to determine college students' daily image information needs, asking about their favorite retrieval systems, the reasons for their preference, their most recent image search requests including their goals, and their typical image search needs.

Researchers often combined different research methods to triangulate their data. Survey and interview were frequently used together (e.g., Beaudoin, 2014; Choi \& Rasmussen, 2003; Huang \& Kelly, 2013), and task analysis was also often used with a think-aloud method (e.g., Choi, 2013; Matusiak, 2006; Wu et al., 2004). 
Table 1. Research methods used

\begin{tabular}{|c|c|c|}
\hline $\begin{array}{l}\text { Research } \\
\text { Method }\end{array}$ & Frequency & References \\
\hline $\begin{array}{l}\text { Survey } \\
\text { Questionnaire }\end{array}$ & 25 & $\begin{array}{l}\text { Beaudoin (2014); Beaudoin (2016); Beaudoin \& Brady (2011); } \\
\text { Bridges \& Edmunson-Morton (2011); Chen (2001); Choi (2010); } \\
\text { Choi (2013); Choi \& Hsieh-Yee (2010); Choi \& Rasmussen } \\
\text { (2002); Choi \& Rasmussen (2003); Conniss et al. (2002); } \\
\text { Graham \& Bailey (2006); Hastings (1999); Huang \& Kelly } \\
\text { (2013); Lee \& Neal (2010); Matusiak (2006); Matusiak et al. } \\
\text { (2019a,b); McBride (2006); Ménard (2011); Ménard \& } \\
\text { Khashman (2014); Pisciotta et al. (2005); Treat \& Judkins } \\
\text { (2018); Yoon (2010); Yoon (2011) }\end{array}$ \\
\hline Interview & 21 & $\begin{array}{l}\text { Beaudoin (2014); Beaudoin (2016); Beaudoin \& Brady (2011); } \\
\text { Chen (2001); Choi \& Rasmussen (2002); Choi (2010); Choi \& } \\
\text { Rasmussen (2003); Conniss et al. (2002); Göker et al. (2016); } \\
\text { Graham \& Bailey (2006); Hastings (1999); Huang \& Kelly } \\
\text { (2013); Konkova et al. (2016); Matusiak (2006); Matusiak et al. } \\
\text { (2019a, b); McBride (2006); Sedghi et al. (2013); Shankar et al. } \\
\text { (2018); Treat \& Judkins (2018); Wu et al. (2004) }\end{array}$ \\
\hline $\begin{array}{l}\text { Query } \\
\text { Analysis }\end{array}$ & 16 & $\begin{array}{l}\text { Armitage \& Enser (1997); Choi (2013); Choi \& Hsieh-Yee } \\
\text { (2010); Choi \& Rasmussen (2003); Chung \& Yoon (2011); } \\
\text { Conniss et al. (2002); De-Arteaga et al. (2015); Deng et al. } \\
\text { (2019); Goodrum (2005); Hastings (1999); Hollink et al. (2011); } \\
\text { Jansen (2008); Konkova et al. (2016); Pu (2008); Tsikrika et al. } \\
\text { (2012); Yoon \& Chung (2011) }\end{array}$ \\
\hline Task Analysis & 10 & $\begin{array}{l}\text { Chen (2001); Choi (2013); Fry (1998); Fukumoto \& Akahori } \\
\text { (2002); Given et al. (2007); Jörgensen et al. (2014); Matusiak } \\
\text { (2006); Ménard (2011); Petrelli \& Clough (2012); Wu et al. } \\
\text { (2004) }\end{array}$ \\
\hline $\begin{array}{l}\text { Literature } \\
\text { Review }\end{array}$ & 10 & $\begin{array}{l}\text { Albertson (2015); Beaudoin (2005); Benson (2015); Bush (2007); } \\
\text { Enser (2000); Enser et al. (2007); Forsyth (1999); Matusiak } \\
\text { (2017); Simor (2003); Woll (2005) }\end{array}$ \\
\hline Think Aloud & 8 & $\begin{array}{l}\text { Choi (2010); Choi (2013); Conniss et al. (2002); Hung (2005); } \\
\text { Matusiak (2006); Pisciotta et al. (2005); Sedghi et al. (2013); Wu } \\
\text { et al. (2004) }\end{array}$ \\
\hline $\begin{array}{l}\text { Log Data } \\
\text { Analysis }\end{array}$ & 7 & $\begin{array}{l}\text { Choi (2010); Hepburn \& Fiscella (2006); Hung (2005); Matusiak } \\
\text { (2006); Pisciotta et al. (2005); Pu (2008); Tsikrika et al. (2012) }\end{array}$ \\
\hline Observation & 6 & $\begin{array}{l}\text { Conniss et al. (2002); Göker et al. (2016); Lundh \& } \\
\text { Alexandersson (2012); Matusiak (2006); Pisciotta et al. (2005); } \\
\text { Wu et al. (2004) }\end{array}$ \\
\hline $\begin{array}{l}\text { Content } \\
\text { Analysis }\end{array}$ & 3 & Angus et al. (2010); Neal (2010); Stvilia \& Jörgensen (2010) \\
\hline $\begin{array}{l}\text { Photo Diary } \\
\text { Analysis }\end{array}$ & 2 & Gabridge et al. (2008); Shankar et al. (2018) \\
\hline Case Study & 2 & Ercegovac (2012); Matusiak (2013) \\
\hline
\end{tabular}




\begin{tabular}{|l|l|l|}
\hline Focus Group & 2 & Pisciotta et al. (2005); Treat \& Judkins (2018) \\
$\begin{array}{l}\text { Google } \\
\text { Analytics }\end{array}$ & 1 & Chen et al. (2010) \\
\hline $\begin{array}{l}\text { Citation } \\
\text { Analysis }\end{array}$ & 1 & Chu (2001) \\
\hline
\end{tabular}

\section{Users Targeted}

The most common user group in the studies were professionals of various types. For example, De-Arteaga et al. (2015) and Tsikrika et al. (2012) studied the image search behavior of medical professionals. Treat and Judkins (2018) opted for filmmakers' image informationseeking behavior. Taking a different approach, Beaudoin (2014) investigated image use among archaeologists, architects, art historians, and artists.

Of the literature reviewed, 20 studies recruited students as participants to investigate everyday image information behavior. Despite this high number, only a handful of studies (Huang \& Kelly, 2013; Matusiak, 2013; Matusiak et al., 2019a; Matusiak et al., 2019b) in our dataset intentionally targeted the information needs and seeking behavior of students. The remaining studies examined the daily needs of general image searchers through the eyes of students.

We describe the third most common user group as general image users. Fourteen articles sought to understand the image needs and/or image-seeking behaviors of people in their daily lives. These studies on general image users utilized data obtained from a search engine or website. For example, Yoon and Chung (2011) analyzed 474 questions obtained from a social Q\&A site, and Jansen (2008) obtained 4,500 image queries on the web, then randomly selected 587 queries for analysis.

The remaining studies investigated bi/multilingual users, seniors, or museum visitors.

Table 2. Types of users investigated in previous studies

\begin{tabular}{|c|c|c|}
\hline User Group & Frequency & References \\
\hline $\begin{array}{l}\text { Users by } \\
\text { Profession }\end{array}$ & 24 & $\begin{array}{l}\text { Beaudoin (2005); Beaudoin (2014); Beaudoin (2016); } \\
\text { Beaudoin \& Brady (2011); Bridges \& Edmunson-Morton } \\
\text { (2011); Chen et al. (2010); Choi \& Rasmussen (2002); Choi } \\
\text { \& Rasmussen (2003); Chu (2001); De-Arteaga et al. (2015); } \\
\text { Enser (2000); Enser et al. (2007); Fry (1998); Göker et al. } \\
\text { (2016); Goodrum (2005); Graham \& Bailey (2006); Hollink } \\
\text { et al. (2011); Hung (2005); Jörgensen et al. (2014); } \\
\text { Konkova et al. (2016); McBride (2006); Sedghi et al. } \\
\text { (2013); Treat \& Judkins (2018); Tsikrika et al. (2012) }\end{array}$ \\
\hline Students & 20 & $\begin{array}{l}\text { Chen (2001); Choi (2010); Choi (2013); Choi \& Hsieh-Yee } \\
\text { (2010); Choi \& Rasmussen (2002); Choi \& Rasmussen } \\
\text { (2003); Ercegovac (2012); Gabridge et al. (2008); Goodrum } \\
\text { (2005); Huang \& Kelly (2013); Jörgensen et al. (2014); Lee } \\
\text { \& Neal (2010); Lundh \& Alexandersson (2012); Matusiak } \\
\text { (2006); Matusiak (2013); Matusiak et al. (2019a,b); } \\
\text { Shankar et al. (2018); Wu et al. (2004); Yoon (2011) }\end{array}$ \\
\hline General Users & 13 & Armitage \& Enser (1997); Chung \& Yoon (2011); Deng et \\
\hline
\end{tabular}




\begin{tabular}{|l|l|l|}
\hline & & $\begin{array}{l}\text { al. (2019); Forsyth (1999); Fukumoto \& Akahori (2002); } \\
\text { Hastings (1999); Hepburn \& Fiscella (2006); Jansen (2008); } \\
\text { Matusiak (2017); Pu (2008); Wu et al. (2004); Yoon } \\
\text { (2010); Yoon \& Chung (2011) }\end{array}$ \\
\hline $\begin{array}{l}\text { Bi/Multilingual } \\
\text { Users }\end{array}$ & 2 & Ménard \& Khashman (2014); Petrelli \& Clough (2012) \\
\hline Seniors & 1 & Given et al. (2007) \\
\hline $\begin{array}{l}\text { Museum } \\
\text { Visitors }\end{array}$ & 1 & Ménard (2011) \\
\hline
\end{tabular}

\section{Images Types Investigated}

Authors of the reviewed studies examined a broad range of image types including general images, archival or historic images, academic images, professional images, artistic images, journalistic images, and medical images. We should note that these image types are not mutually exclusive. For example, Graham and Bailey (2006) consider images used by art historians, which we classified here as both archival or historic images and artistic images.

\section{General Images}

General images, which did not fit a specific domain, were the most commonly investigated. For example, Jansen (2008) studied image query structuring by analyzing a sample of queries from Excite, a search engine at the time of data collection. Queries ranged from "microwave pictures" to "New York City pictures," representing a broad range of image types. In many cases, images in this general group fall into the category of everyday life information practices (Shankar, 2018). As an example, while Bridges and Edmunson-Morton (2011) surveyed college students about their academic search habits, the authors also asked questions about image searches for "personal/pleasure" purposes.

\section{Archival or Historic Images}

This category includes images found within museums and archives, images that could be described as historic, and images that depict a "museum object" (Ménard, 2011). For example, the experiment designed by Petrelli and Clough (2012) used images from the St. Andrews image archive. Bridges and Edmunson-Morton (2011) asked participants to describe the search process they would use to find an image of "people logging in Oregon forests in the 1930s or 1940s" (p. 27). Ménard (2011) compared user attempts to retrieve specific museum object images with different search engines.

\section{Academic Images}

Academic images are those used by students and teachers, ranging from elementary to post-graduate studies. For example, Huang and Kelly (2013) looked at the image information needs and seeking behavior of Chinese undergraduate students. While the survey in this study included some everyday images that would fit into the general images category, questions and responses also related to images for coursework purposes, such as PowerPoint presentations and papers. 


\section{Professional Images}

Professional images are those used in a workplace setting. Examples include stock photography sought by graphic designers (Konkova et al. 2016) and footage sought by documentary filmmakers (Treat \& Judkins, 2018).

\section{Artistic Images}

The artistic images category includes images used for or related to fine art. For example, Hepburn \& Fiscella (2006) compared sample sets of records taken from the AMICO (Art Museum Image Consortium) database. Graham and Bailey (2006) looked at images used by art historians, including images found in museum and gallery collections.

\section{Journalistic Images}

Journalistic images include those stored in journalism or "News wire" databases as well as images used by journalists or news organizations. For example, Hung (2005) tasked journalism students with searching for images using the AccuNet/Associated Press Photo Archive. Göker et al. (2016) observed the image search habits of journalists.

\section{Medical Images}

Images in this category are used for or related to healthcare. For example, Tsikrika et al. (2012) used query logs from a medical search engine that provides access to a collection of 250,000 radiology images. Users of medical images, however, are not necessarily professionals. For example, focusing on seniors and usability, Given (2007) explored an image-based retrieval interface for drug information.

Table 3. Types of images investigated

\begin{tabular}{|c|c|c|}
\hline Image Type & Frequency & References \\
\hline General Images & 21 & $\begin{array}{l}\text { Bridges \& Edmunson-Morton (2011); Choi } \\
\text { (2013); Chung \& Yoon (2011); Deng et al. } \\
\text { (2019); Forsyth (1999); Fukumoto \& Akahori } \\
\text { (2002); Gabridge et al (2008); Hastings (1999); } \\
\text { Huang \& Kelly (2013); Lee \& Neal (2010); } \\
\text { Matusiak (2017); Matusiak et al. (2019a,b); } \\
\text { McBride (2006); Ménard \& Khashman (2014); } \\
\text { Neal (2010); Pu (2008); Shankar et al. (2018); } \\
\text { Yoon (2010); Yoon (2011); Yoon \& Chung } \\
\text { (2011) }\end{array}$ \\
\hline $\begin{array}{l}\text { Archival or Historic } \\
\text { Images }\end{array}$ & 21 & $\begin{array}{l}\text { Armitage \& Enser (1997); Beaudoin (2016); } \\
\text { Beaudoin \& Brady (2011); Bridges \& } \\
\text { Edmunson-Morton (2011); Chen et al. (2010); } \\
\text { Choi \& Hsieh-Yee (2010); Choi \& Rasmussen } \\
\text { (2002); Choi \& Rasmussen (2003); Enser } \\
\text { (2000); Ercegovac (2012); Fry (1998); Graham } \\
\text { \& Bailey (2006); Hung (2005); Jörgensen et al. } \\
\text { (2014); Matusiak (2006); Matusiak (2013); } \\
\text { Ménard (2011); Petrelli \& Clough (2012); }\end{array}$ \\
\hline
\end{tabular}




\begin{tabular}{|c|c|c|}
\hline & & $\begin{array}{l}\text { Stvilia \& Jörgensen (2010); Treat \& Judkins } \\
\text { (2018); Woll (2005); }\end{array}$ \\
\hline Academic Images & 9 & $\begin{array}{l}\text { Angus et al. (2010); Bridges \& Edmunson- } \\
\text { Morton (2011); Gabridge et al. (2008); } \\
\text { Goodrum (2005); Huang \& Kelly (2013); } \\
\text { Lundh \& Alexandersson (2012); Matusiak } \\
\text { (2013); Matusiak et al. (2019a,b) }\end{array}$ \\
\hline Professional Images & 8 & $\begin{array}{l}\text { Beaudoin (2014); Beaudoin (2016); Choi \& } \\
\text { Hsieh-Yee (2010); Enser (2000); Göker et al. } \\
\text { (2016); Hollink et al. }(2011) \text {; Konkova et al. } \\
\text { (2016); Treat \& Judkins (2018) }\end{array}$ \\
\hline Artistic Images & 6 & $\begin{array}{l}\text { Beaudoin (2014); Beaudoin (2016); Beaudoin } \\
\text { \& Brady (2011); Enser (2000); Graham \& } \\
\text { Bailey (2006); Hepburn \& Fiscella (2006) }\end{array}$ \\
\hline Journalistic Images & 5 & $\begin{array}{l}\text { Chen et al. (2010); Enser (2000); Göker et al. } \\
\text { (2016); Hollink et al. (2011); Hung (2005) }\end{array}$ \\
\hline Medical Images & 4 & $\begin{array}{l}\text { De-Arteaga et al. (2015); Given et al. (2007); } \\
\text { Sedghi et al. (2013); Tsikrika et al. (2012) }\end{array}$ \\
\hline
\end{tabular}

\section{Identified Image Information Needs}

Based on our review, we identified seven image information need categories: 1) entertainment, 2) illustration, 3) aesthetic appreciation, 4) knowledge construction, 5) engagement, 6) inspiration, and 7) social interactions. These categories are not mutually exclusive; for example, one image may illustrate an idea in a presentation due to its representative qualities as well as its aesthetic value.

\section{Entertainment}

Many image users expressed the need for entertainment and leisure. Huang and Kelly (2013) presented how users' motivation for web image searching is often for entertainment purposes (78\% of responses). On the same note, Yoon (2011) showed that most everyday image information needs are to satisfy one's curiosity, gain knowledge, or entertain. Besides using images for entertainment purposes, image users also searched for images simply because they like the content of the image (Yoon \& Chung, 2011). Individuals also sought images to support leisure activities such as hobbies or travel (Ménard, 2011).

\section{Illustration}

One of the most prominent image information needs was illustration - the explanation or clarification of details. Illustration needs were among users in professional and academic settings, such as students, lecturers, researchers, and doctors. Creating presentation slides or preparing study materials were frequently mentioned image use cases (e.g., Beaudoin, 2014; Huang \& Kelly, 2013; Matusiak et al., 2019a,b). In medical settings, clinicians use images to support patient diagnoses and colloquia presentations (Beaudoin, 2014). 


\section{Aesthetic Appreciation}

Another prominent information need concerned images' aesthetic qualities (e.g. Beaudoin, 2014; Huang \& Kelly, 2013; Lundh \& Alexandersson, 2012; Matusiak et al., 2019b). From seeking images for desktop backgrounds (Huang \& Kelly, 2013) to other images for aesthetic appreciation (e.g., images of people, objects, events, times, and scenes) (Beaudoin, 2014), aesthetic appreciation needs were diverse.

\section{Knowledge Construction}

People search for images to support knowledge construction. Conniss and colleagues (2002) aptly categorize this need into four categories: information processing, information dissemination, learning, and ideation. Another way to approach knowledge construction is through Anderson and Krathwohl's (2001) conceptualization of Bloom's taxonomy into lowerorder and higher-order thinking skills. According to Bloom's Taxonomy (as cited in Anderson and Krathwohl, 2001 ${ }^{1}$ ) there are six main levels of knowledge construction: 1) remembering (retrieving, recognizing, and recalling knowledge), 2) understanding (constructing meaning), 3) applying (implementing what has been learned), 4) analyzing (breaking material into constituent parts), 5) evaluating (making judgments based on criteria and standards), and 6) creating (putting elements together to plan or produce). Later, Anderson and Krathwohl (2001) grouped the abilities to remember and understand into lower-order thinking skills and analyze, evaluate, and create into higher-order thinking skills. The image information needs identified in the existing literature supported both lower-order and higher-order thinking skills.

Lower-level Thinking Skills. At the lower level of Bloom's (1956) Taxonomy, images are reported to support knowledge recall, and users sought images based on this ability. Images may support knowledge recall as they can function as "memory adjuncts" or "mnemonic aids" as discussed by Matusiak (2013). Students participating in Matusiak's study (2013) reported that images in PowerPoint presentations helped them recall lecture material. As such, images can play a "mediating function in memory and learning" (Matusiak, 2013, p.1587). Still at the lower level of cognitive processing or thinking skills, images have a unique ability to convey a tremendous amount of information instantly, and, when used properly, can augment the understanding of knowledge, especially abstract knowledge. User groups by profession in Beaudoin (2014) utilize images to help themselves or others better understand their fields. For example, architects in Beaudoin's (2014) study sought images for architectural information, such as design styles. Students also seek images to understand abstract knowledge, as reported in Beaudoin (2014), Conniss et al. (2002), and Huang and Kelly (2013). Huang and Kelly (2013) also found that instructors use images to accompany course content to make abstract information more accessible to audiences. The participants in Beaudoin's (2014) study similarly mentioned that images make it easier to translate abstract information in learning contexts.

Higher-level Thinking Skills. Educators also search for images that may develop their students' critical thinking skills. When aligned with learning content, images may be used to promote questions, helping students to examine and contemplate content more deeply (Beaudoin, 2014). Furthermore, images can also be used to test students' knowledge and assess whether deep learning is achieved (Beaudoin, 2014).

\footnotetext{
1 This classification system of cognitive thinking skills was developed by Benjamin Bloom, and then later revised by Anderson and Krathwohl (2001)
} 


\section{Engagement}

Users search for images to grab audiences' attention and keep them engaged. Instructors and students exemplify this need. For example, Beaudoin (2014) and Matusiak et al. (2019a, b) report that students assume that image-rich presentations are more attractive and keep audiences engaged.

\section{Inspiration}

Searching for images may lead to inspiration, especially for creative user groups. This is true for artists (Chung \& Yoon, 2011) as well as professionals, such as architects (Chidlow, 1994) and museum curators (McBride, 2006). General image users also search for inspiration (Beaudoin, 2014). This need is not always lofty; image searchers need inspiration for consumer or travel purchases, too (Yoon, 2011).

\section{Social Interactions}

People communicate through images. This is especially true with the increasing ease of searching, downloading, and sharing pictures. For example, users search for images to trigger emotions (Beaudoin, 2014). Users also seek images to convey emotion, as suggested by Choi and Rasmussen (2003). When images are used to trigger and convey feelings and emotions, they can "close a gap that existed in the physical, intellectual, or psychological states of people" (Beaudoin, 2014, p. 30).

\section{Table 4. Identified image information needs}

\begin{tabular}{|c|c|c|}
\hline Image Need & Frequency & References \\
\hline Illustration & 11 & $\begin{array}{l}\text { Beaudoin (2014); Bridges \& Edmunson-Morton (2011); } \\
\text { Chung \& Yoon (2011); Conniss et al. (2002); Deng et al. } \\
\text { (2019); Göker et al. (2016); Huang \& Kelly (2013); Lundh } \\
\text { \& Alexandersson (2012); Matusiak et al. (2019b); McBride } \\
\text { (2006); Sedghi et al. (2011) }\end{array}$ \\
\hline $\begin{array}{l}\text { Knowledge } \\
\text { Construction }\end{array}$ & 11 & $\begin{array}{l}\text { Angus et al. (2010); Beaudoin (2014); Choi (2010); Conniss } \\
\text { et al. (2002); Deng et al. (2019); Graham \& Bailey (2006); } \\
\text { Huang \& Kelly (2013); Matusiak, (2013); Matusiak et al. } \\
\text { (2019a); McBride (2006); Sedghi et al. (2011) }\end{array}$ \\
\hline Inspiration & 10 & $\begin{array}{l}\text { Beaudoin (2014); Chidlow (1994); Chung \& Yoon (2011); } \\
\text { Conniss et al. (2002); Göker et al. (2016); Graham \& Bailey } \\
\text { (2006); Matusiak et al. (2019a); McBride (2006); Wu et al. } \\
\text { (2004); Yoon (2011) }\end{array}$ \\
\hline $\begin{array}{l}\text { Aesthetic } \\
\text { Appreciation }\end{array}$ & 8 & $\begin{array}{l}\text { Beaudoin (2014); Chung \& Yoon (2011); Conniss et al. } \\
\text { (2002); Göker et al. (2016); Huang \& Kelly (2013); Lundh } \\
\text { \& Alexandersson (2012); Matusiak et al. (2019b); Shankar } \\
\text { et al. (2018) }\end{array}$ \\
\hline Entertainment & 5 & $\begin{array}{l}\text { Choi (2010); Huang \& Kelly (2013); Ménard (2011); Yoon } \\
\text { (2011); Yoon \& Chung (2011) }\end{array}$ \\
\hline $\begin{array}{l}\text { Social } \\
\text { Interactions }\end{array}$ & 5 & $\begin{array}{l}\text { Beaudoin (2014); Choi \& Rasmussen (2003); Deng et al. } \\
\text { (2019); Neal (2010); Yoon (2010) }\end{array}$ \\
\hline
\end{tabular}


\begin{tabular}{l|l|l} 
Engagement & 3 & Beaudoin (2014); Matusiak et al. (2019a,b)
\end{tabular}

\section{Image Information Search Behaviors}

In our collected literature, five image information search strategies and behaviors appeared predominant: 1) keyword-based search, 2) browsing, 3) use of search tools, 4) query specialization and reformulation, and 5) other image search related discussions regarding copyright, ethical/legal aspects, and validity of images.

\section{Keyword-based Search}

Keyword-based searching is a common strategy for seeking images. For example, Matusiak (2017) notes that half of her participants preferred keyword searches, whereas "33 percent said they would prefer to browse, and 17 percent indicated no preference" (p.484). Others similarly report a strong preference for keyword-based searching (e.g., Huang \& Kelly, 2013; Matusiak, 2006; Fukunmoto \& Akahori, 2002). As Ménard and Khashman (2014) state, "The image searchers prefer to search with various metadata-based keywords related to the content of the image they are looking for, the events taking place or people that appear in the picture" (p. 62). Furthermore, when using a keyword-based strategy, people prefer simplicity. Users tend to use very short queries, such as isolated terms or simple expressions rather than well-informed phrases (Choi \& Hsieh-Yee, 2010; Hollink et al., 2011; Jansen, 2008; Matusiak, 2006; Petrelli \& Clough, 2012; Pu, 2008; Tsilrika et al., 2012).

\section{Browsing}

Browsing is also a commonly employed image search strategy. For example, users in Matusiak (2006) reported that they started with keyword searches but enjoyed browsing later, especially if the browsing feature offered different subject categories to aid their search and keep their interest. Göker et al. (2015), focusing on creative professionals, found that they used a targeted keyword search strategy, but, when it came to broader searches within topics, they opted for a category search.

It is worth noting that the search engine's affordances also influence browsing behavior. When search engines have images sorted by categories, users are reported to prefer the random browse category over categories sorted by content and style (Hastings, 1999). Pu (2008) describes that users who prefer browsing are more willing to do so when reduced-size images are available (i.e., thumbnails).

\section{Search Tools}

Users employ various web-based tools to search for images, but Google Images is widely adopted as part of users' search strategies regardless of user type or profession. For example, Konkova et al. (2016), Göker et al. (2015), and McBride (2006) found that creative professionals used Google Images for ideation. Google Images is also a primary source of visual materials for student presentations (Matusiak et al., 2019a,b).

When concerned about the quality and validity of citation information of images, users may opt to use specialized image sources like museum websites (Matusiak et al., 2019b). When a professional user group has access to designated image databases especially for their work, they tend to use those databases to acquire images. For example, McBride (2006) reported the daily use of internal databases by curators to acquire digital images. 


\section{Query Specialization and Reformulation}

The image search process involves exploration and refinement. For example, Respondents in Ménard's (2011) study described how they usually search for images: the majority of participants first used keywords, then titles and names, and some confirmed using advanced search functionalities. Choi's (2013) study found that users start with partial information and specific information related to an image to express their need in short keywords. The process of starting with specific information or contextual information to see what is available in a broader information space is defined as specialization. Based on the results of the initial query, users refine their search. This process is reformulation. Reformulation includes more topical terms referring to format/genre, object, place, organization, and person related to the image. Both specialization and reformulation are the most frequently used search strategies (Choi, 2013; Tsikrika, 2012).

\section{Copyright, Ethical and Legal Aspects, and Validity}

When considering copyright, ethical and legal aspects, and validity associated with images, the identified studies indicate that professional groups and graduate students pay more attention than undergraduate students (e.g., Gabridge et al., 2018; Matusiak et al., 2019b; Treat \& Judkins, 2018). For example, none of the students in Bridges and Edmunson-Morton (2011) expressed copyright concerns when searching for images for their assignments. Furthermore, most students do not follow links, read the text surrounding the image, or check permissions (Matusiak et al., 2019b). According to Matusiak et al. (2019b), this is behavior especially true for classroom presentations.

Table 5. Identified image information search behaviors

\begin{tabular}{|l|l|l|}
\hline Search Behaviors & Frequency & References \\
\hline $\begin{array}{l}\text { Keyword-based } \\
\text { Search }\end{array}$ & 18 & $\begin{array}{l}\text { Albertson (2015); Choi (2010); Choi \& Hsieh-Yee (2010); } \\
\text { Enser (2000); Fukunmoto \& Akahori (2002); Göker } \text { et al. } \\
\text { (2016); Goodrum (2005); Hepburn \& Fiscella (2006); } \\
\text { Hollink } \text { et al. (2011); Huang \& Kelly (2013); Jansen } \\
\text { (2008); Matusiak (2006); Matusiak, (2017); McBride } \\
\text { (2006); Ménard \& Khashman (2014); Petrelli \& Clough } \\
\text { (2012); Pu (2008); Tsilrika } \text { et al. (2012) }\end{array}$ \\
\hline Browsing & \multirow{2}{*}{$\begin{array}{l}\text { Albertson (2015); Beaudoin (2005); Chen } \text { et al. (2010); } \\
\text { Choi (2010); De-Arteaga } \text { et al. (2015); Forsyth (1999); } \\
\text { Göker } \text { et al. (2016); Graham \& Bailey (2006); Hastings } \\
\text { (1999); zseMatusiak (2006); Pu (2008); Wu } \text { et al. (2004) }\end{array}$} \\
\hline Search Tools & 9 & $\begin{array}{l}\text { Bridges \& Edmunson-Morton (2011); Deng } \text { et al. (2019); } \\
\text { Gabridge } \text { et al. (2008); Goodrum (2005); Konkova } \text { et al. } \\
\text { (2016); Matusiak et al. (2019a,b); McBride (2006); } \\
\text { Ménard \& Khashman (2014) }\end{array}$ \\
\hline $\begin{array}{l}\text { Query } \\
\text { Specialization and } \\
\text { Reformulation }\end{array}$ & 8 & $\begin{array}{l}\text { (20013); Fukumoto \& Akahori (2002); Goodrum } \text { et al. (2016); Jansen (2008); Matusiak } \\
\text { (2006); Ménard (2011); Tsikrika (2012) }\end{array}$ \\
$\begin{array}{l}\text { Copyright, Ethical } \\
\text { and Legal Aspects, }\end{array}$ & 5 & $\begin{array}{l}\text { Bridges \& Edmunson-Morton (2011); Gabridge } \text { et al. } \\
\text { (2018); Göker } \text { et al. (2016); Matusiak et al. (2019b); Treat }\end{array}$ \\
\hline
\end{tabular}




\section{Image Search Obstacles}

The literature revealed seven primary categories of image search obstacles that prevent or interfere with a user's ability to find the images they seek: 1) semantic problems 2) contentbased issues, 3) technical limitations, 4) issues of aboutness, 5) inclusivity issues, 6) search skills, and 7) cognitive overload.

\section{Semantic Problems}

Semantic problems refer to issues with the terminology used in image retrieval systems, as well as the standardization of that language through thesauri and other tools (Hastings, 1999). Semantic issues are particularly important because, as Enser et al. (2007) note, "users' interest in images lies with their inferred semantic content, and a retrieval facility which returns candidate images lacking in semantic integrity has little or no operational value" (p. 468). For example, In their 2010 study, Choi and Hsieh-Yee observed that, while experts may reference terms from professional literature (such as the Thesaurus for Graphic Materials II) to identify precise description terminology, those terms could be lost on the non-expert user. The authors suggest that search platforms might present format and genre terminology in language that is more accessible to the non-specialist user. According to Woll (2005), many thesauri for humanities emphasize the use of common search terms. However, there is a need for other types of search terms, such as proper nouns (Woll, 2005).

\section{Content-based Issues}

Hastings (1999) defines content-based issues as those related to the identification of image attributes. The author provides the example of searching for the term "Homer," which retrieves images of the Greek Homer, Homer Simpson, Winslow Homer, and more. Even when the author attempted to find "visually similar images" of a bust of the Greek Homer, the search results were questionable and problematic — without showing other bronze busts or image of Homer.

In some instances, rather than describing the image itself, users will search by relating the target image to an existing image. To help users better articulate image content needs using this alternative method, Chung and Yoon (2011) recommend that image retrieval systems allow users to describe the target image (implicit method), as well as provide the option to directly input a URL or sample image similar to the target image (explicit method).

According to $\mathrm{Pu}$ (2008), content-based image retrieval technologies that focus on perceptual image attributes are not enough to ensure successful queries. $\mathrm{Pu}(2008)$ recommended adequate image indexing and the use of both conceptual and perceptual features of the image for effective retrieval. Enser (2000) argues that "While both concept-based and content-based approaches suffer from operational limitations, the further development of a hybrid image retrieval paradigm which combines the two approaches makes a potentially valuable contribution to the research agenda for visual image retrieval" (p.199).

\section{Technical Limitations}

Hastings (1999) describes technical problems as issues with load time, bandwidth, standard formats, color match systems, image file size, compression losses, and resolution 
variables. A decade later, Huang and Kelly (2013) note that similar technical issues persist; 66.86 percent of participants in their study reported that the size, format, and resolution of images are often unsatisfactory.

While commonly used image retrieval tools such as Google Images can filter results by size and color, it is hard to say whether technical image search issues have been resolved on a universal level. The prevalence of specific technical problems such as bandwidth, lack of standard formats, and compression losses depends on multiple factors including the database being searched, the user's specific format needs, and the user's connection speed.

\section{Issues of Aboutness}

The topicality of the retrieved images was the primary issue in several studies. In Huang and Kelly's (2013) study, approximately 38 percent of respondents reported that most of the image search results were not related to their desired topic. Sometimes, issues of aboutness are due to an overabundance of images, such as with Google's Image Search function (Sedghi et al. (2011). These issues may stem from subjectivity. Using think-aloud and transaction log analysis, Hung (2005) found that undergraduates using the AccuNet/AP Photo Archive for subjective images required more search tactics and reformulation than searching for a specific or general image. As Hung (2005) states, this "indicates that it was much harder for the subjects to query and search for photos, which contain abstract or subjective meaning” (p. 341).

\section{Inclusivity Issues}

Image users encounter problems when search systems do not take into account users' cultural and linguistic aspects (Simor, 2003; Stvilia \& Jörgensen, 2010; Wallace, 2001; Woll, 2005). When it comes to bilingual and multilingual image searchers, semantic problems can be particularly challenging. A study by Pertrelli and Clough (2012) revealed the issues that can arise when machine translation of search terminology is not accurate. The authors describe query translation as "difficult and often error-prone" (p.214). Similarly, Matusiak (2006) and Ménard (2011) find that the current multilingual features of image retrieval systems are not successfully supporting or appealing enough to multilingual users. Woll (2005) also specifically calls for multi-lingual thesauri to support users searching diverse cultural heritage materials and representations of a variety of knowledge domains.

\section{Search Skills}

Studies such as Choi (2001), Graham and Bailey (2006), and Matusiak (2006) discuss the issues related to the user's search skills. Graham and Bailey (2006) note that while some of their participants (art historians) complained about the lack of access to the technology, others did not have a general understanding of how to use the available technology and worried about the learning curve. In a different study, Matusiak (2006) found that participants who are less confident with their digital search skills tend to rely on browsing functionality provided for image search than using keyword search. On the contrary, participants who felt more confident about their computer skills were more likely to use keyword search.

\section{Cognitive Overload Issues}

Cognitive overload describes the disorientation users experience when facing complex image searches. In a study by Gabridge et al. (2008), participants reported that topical searching was more time-consuming and difficult than known-item searching. With overwhelmingly many tools to choose from, the participants reported uncertainty on how to begin a broad topical image 
search. Designers of image search engines may also need to account for users with minimal search experience. For example, Given et al. (2007) recommend incorporating features for cognitive reassurance for senior users who have cognitive overload issues when searching for image-based drug information.

Table 6. Identified image search obstacles

\begin{tabular}{|l|l|l|}
\hline $\begin{array}{l}\text { Search } \\
\text { Obstacles }\end{array}$ & Frequency & References \\
\hline $\begin{array}{l}\text { Semantic } \\
\text { Problems }\end{array}$ & 10 & $\begin{array}{l}\text { Choi \& Hsieh-Yee (2010); Deng } \text { et al. (2019); Enser (2000); } \\
\text { Enser } \text { et al. (2007); Fry (1998); Goodrum (2005); Huang \& } \\
\text { Kelly (2013); Jörgensen } \text { et al. (2014); Lee \& Neal (2010); } \\
\text { Ménard \& Khashman (2014) }\end{array}$ \\
\hline $\begin{array}{l}\text { Content-based } \\
\text { Issues }\end{array}$ & 8 & $\begin{array}{l}\text { Beaudoin \& Brady (2011); Chung \& Yoon (2011); Enser } \\
\text { (2000); Enser } \text { et al. (2007); Ercegovac (2012); Hastings } \\
\text { (1999); Ménard (2011); Pu (2008) }\end{array}$ \\
\hline $\begin{array}{l}\text { Technical } \\
\text { Limitations }\end{array}$ & 6 & $\begin{array}{l}\text { Göker } \text { et al. (2016); Graham \& Bailey (2006); Hastings } \\
\text { (1999); Huang \& Kelly (2013); Neal (2010); Yoon (2011) }\end{array}$ \\
\hline $\begin{array}{l}\text { Issues of } \\
\text { Aboutness }\end{array}$ & 6 & $\begin{array}{l}\text { Fry (1998); Göker } \text { et al. (2016); Huang \& Kelly (2013); } \\
\text { Hung (2005); Sedghi } \text { et al. (2011); Yoon (2011) }\end{array}$ \\
\hline $\begin{array}{l}\text { Inclusivity } \\
\text { Issues }\end{array}$ & 5 & $\begin{array}{l}\text { Matusiak (2006); Ménard (2011); Petrelli \& Clough (2012); } \\
\text { Pu (2008); Woll (2005) }\end{array}$ \\
\hline Search skills & 3 & $\begin{array}{l}\text { Choi (2010); Huang \& Kelly (2013); Graham \& Bailey } \\
\text { (2006); Matusiak 2006; Matusiak } \text { et al. (2019b); Woll (2005) }\end{array}$ \\
\hline $\begin{array}{l}\text { Cognitive } \\
\text { Overload Issues }\end{array}$ & 3 & $\begin{array}{l}\text { Gabridge } \text { et al. (2008); Given } \text { et al. (2007); Göker } \text { et al. } \\
\text { (2016) }\end{array}$ \\
\hline
\end{tabular}

Many of the studies cited above offer solutions to the search obstacles they highlight. To say whether these issues have been resolved would require additional research. This research could examine whether the recommended solutions - such as more diverse bodies of index terms (Hung, 2005), offering CBIR (Chung \& Yoon, 2011), and options for multilingual users (Matusiak, 2006) - have been implemented across platforms and lead to better search experiences. Following this vein of offering solutions, the next section presents identified research gaps that emerged from this systematic review.

\section{Identified Research Gaps}

This section answers RQ2: "What are the identified research gaps in existing image information needs and behavior studies?", focusing on user expertise, participant selection, and methods. The following themes were identified based on three researchers' regular and iterative weekly discussions as a part of reviewing the collected literature. The issues of 1) discussing different user expertise, 2) participants' recruitment in academia, and 3) heavy use of quantitative research method were observed and agreed upon among the authors.

\section{Explorations of User Expertise}

We did not observe in-depth research on disparities in image information needs and behaviors between general users and expert users or the development of expertise. Also, our 
dataset shows that there is a lack of research on how the digital divide might impact users' image needs and search behaviors. To create more satisfying search experiences, future studies could focus on how users' expertise influences their searches and their subsequent perceived success. This skills-based approach may yield contributions to both image information research and search engine or database design.

\section{Participant Pools Outside of Academia}

Our dataset indicates that convenience sampling has been a popular data collection method, especially recruiting college students as "general users." Twenty studies focused on students, yet only four studies specifically targeted the needs and behavior of students (Huang \& Kelly, 2013; Matusiak, 2013; Matusiak et al., 2019a; Matusiak et al., 2019b). As such, future studies, especially those attempting to capture the behavior of general users, may need to diversify their samples.

\section{Embracing New Methods}

The majority of studies used quantitative approaches, such as query analysis, survey questionnaire, and log data, which echoes previous reviews of overall information behavior research (Aytac \& Slutsky, 2015; Chu, 2015; Matusiak, 2017). Furthermore, the low number of qualitative work found in this study is consistent with the lack of qualitative research in library information science found in previous studies (Chu, 2015; Matusiak, 2017). Though quantitative approaches can determine cause and effect, make predictions, or describe the distribution of characteristics among a population, they are not efficient in uncovering and understanding how people interpret their experiences and what meaning they attribute to their experiences like qualitative approaches (Marriam \& Tisdell, 2016). To investigate image information needs and seeking, researchers may benefit from more of the qualitative techniques found in our review, such as stimulated recall with artifacts (Matusiak et al., 2019b), photo diaries (Gabridge et al., 2008; Shankar et al., 2018), or focus groups (Treat \& Judkins 2018).

\section{Discussion}

In this section, we discuss our suggestions for future research as an extension of Identified Research Gaps discussed above. Based on the literature review, we consider that the following areas need to be further explored in the future: 1) motivations of searching image information, 2) evolving and newly developed image search behaviors with technological developments in image retrieval, and 3) status of, or the appropriate direction for, image information literacy education.

\section{Motivation and its Contexts}

Dovetailing into the aforementioned need for complex qualitative data, our results indicate a lack of in-depth research on how evolving gaps in knowledge motivate the search process. In particular, adopting the lens of information-as-process may be beneficial (Buckland, 1991). Using qualitative approaches, researchers may attempt to understand how a person's state of knowledge and ensuing motivations change throughout the search process (Case \& Given, 2016). Similarly, another area ripe for further research is unpacking the dynamics of how teamwork alters these gaps and motivations. In addition to its practical implications, this line of 
inquiry would align with scholarship that posits that information cannot be removed from contexts, such as social activity (Case \& Given, 2016).

\section{New Technology, New Behavior}

Content-based image retrieval (CBIR) and voice-supported search functions are two areas ripe for further research. Today, Google Images offers the functionality proposed by Chung and Yoon (2011) through CBIR, allowing users to drag and drop an existing image into the search field to provide results that are similar to that image based on color, image, and shape. To understand whether CBIR solves content-based issues, it would be helpful to study the prevalence of this option among other search engines as well as its perceived effectiveness. Additionally, none of the articles examined search behaviors with voice-supported search features. With the widespread use of voice command technologies like Alexa from Amazon that enables new types of image searches with a screen (Schlosser, 2018), image users' evolving search behavior needs to be revisited.

\section{Information and Visual Literacies Instruction}

Engaging students with the topics of copyright law and the ethical use of sources is a perennial problem in information literacy instruction. Bridges and Edmunson-Morton (2011) suggest that undergraduate students would benefit from having visual literacy integrated into standard information literacy instruction to help them locate, evaluate, and legally use the images they find online. As research on image information research continues, a specific focus on prescriptive, intervention-based research may lead to techniques for information and visual literacy education.

Similarly, Albertson (2015) argues that future studies should investigate how visual information can be used to enhance users' literacy. Due to its multidimensional nature, visual information may have the potential to advance other information and collaborative processes (Albertson, 2015). Looking at how image information is utilized in these different information contexts from a holistic view, in addition to looking at specific image retrieval scenarios and tasks, will expand the current image information research to a universal level.

\section{Conclusion}

In this paper, we presented a synthesis of 69 peer-review works on image information needs and image searching behavior. Based on our review, we categorized this line of inquiry into six major categories: research methods used, users targeted, image types investigated, identified image information needs, image information search behaviors, and image search obstacles.

In answering our main research question, "What have we learned so far about image information needs and behaviors?", we found that, across the studies, a broad range of image types were examined, including academic images, archival or historic images, artistic images, and more. People seek and use these images for multiple reasons, including entertainment, illustration, aesthetic needs, knowledge construction, engagement, inspiration, and social interactions. The reviewed studies reported that common strategies for image searches include keyword searches with short queries, browsing, specialization, and reformulation. Also, the 
reviewed studies most frequently employed quantitative research methods and undergraduate participant pools to determine these needs and behavior.

Asking our second supporting question, "What are the identified research gaps in existing image information needs and behavior studies?", we found that researchers may benefit from focusing on user expertise, participant selection, and qualitative methods. Of these categories, the most poignant research gap that may readily be addressed is target user selection. Our findings indicate that students were overly favored as participant pools to determine the image needs and search behaviors of "general users." Although students may be a convenient sample, their needs and behavior may not be representative of other populations. More research needs to examine image needs and search behavior of different groups, such as by age, gender, or profession to have a more complete picture of whether existing image search platforms satisfy user needs.

The field of image information research has burgeoned over the past twenty years. As technological advances occur, new image searching and sharing platforms and features will likely emerge. Some will take greater consideration of user needs and some will fall short. As such, researchers will have plenty to investigate. Nevertheless, to advance the field, we suggest greater use of rich qualitative data and a keen eye on how image needs change throughout the search process. Continued work to understand the complex schemas that form throughout the search process will not only inform database or search engine design features but also enrich the constellation of existing information behavior models at large.

\section{References}

Albertson, D. (2015), "Visual information seeking", Journal of the Association for Information Science and Technology, 66(6), 1091-1105.

Anderson, L. W., \& Krathwohl, D. R. (2001), A Taxonomy for Learning, Teaching, and Assessing: A Revision of Bloom's Taxonomy of Educational Objectives, Longman, New York, NY.

Angus, E., Stuart, D., \& Thelwall, M. (2010), "Flickr's potential as an academic image resource: an exploratory study", Journal of Librarianship and Information Science, 42(4), 268-278.

Aytac, S., \& Slutsky, B. (2015), "Published librarian research, 2008 through 2012: Analyses and perspectives", Collaborative Librarianship, 6(4), 147-159.

Armitage, L. H., \& Enser, P. G. B. (1997), “Analysis of user need in image archives", Journal of Information Science, Vol. 23 No. 4, pp.287-299.

https://doi.org/10.1177/016555159702300403

Beaudoin, J. (2005), "Image and text: A review of the literature concerning the information needs and research behaviors of art historians", Art Documentation: Journal of the Art Libraries Society of North America, Vol. 24 No. 2, pp.34-37.

Beaudoin, J. E. (2007), "Visual materials and online access: Issues concerning content representation", Art Documentation: Journal of the Art Libraries Society of North America, 26(2), 24-28.

Beaudoin, J. (2014), "A framework of image use among archaeologists, architects, art historians and artists", Journal of Documentation, Vol. 70 No.1, pp.119-147. https://doi.org/10.1108/JD-12-2012-0157 
Beaudoin, J. E. (2016), "Content-based image retrieval methods and professional image users", Journal of the Association for information science and technology, 67(2), 350365.

Beaudoin, J. E., \& Brady, J. E. (2011), "Finding visual information: a study of image resources used by archaeologists, architects, art historians, and artists", Art Documentation: Journal of the Art Libraries Society of North America, 30(2), 24-36.

Beebe, C. (2000), "Image indexing for multiple needs", Art Documentation: Journal of the Art Libraries Society of North America, 19(2), 16-21.

Benson, A. C. (2015), "Image descriptions and their relational expressions: a review of the literature and the issues", Journal of Documentation.

Bridges, L., \& Edmunson-Morton, T. (2011), "Image-seeking preferences among undergraduate notice researchers", Evidence Based Library and Information Practice, Vol. 6 No. 1, pp.24-40. https://doi.org/10.18438/B82G9M

Buckland, M. K. (1991), "Information as thing", Journal of the American Society for Information Science, Vol. 42, pp.351-360.

Bush, M. D. (2007), "Facilitating the integration of culture and vocabulary learning: The categorization and use of pictures in the classroom", Foreign Language Annals, 40(4), 727-745.

Case, D., \& Given, L. (2016), Looking for Information: A Survey of Research on Information Seeking, Needs, and Behavior (4th ed.), Emerald Publishing, Bingley, UK.

Chen, H. L. (2001), "An analysis of image retrieval tasks in the field of art history", Information Processing \& Management, 37(5), 701-720.

Chen, H., Kochtanek, T., Burns, C. S., \& Shaw, R. (2010), “Analyzing users' retrieval behaviours and image queries of a photojournalism image database", Canadian Journal of Information and Library Science, Vol. 34 No. 3, pp.249-270. https://doi.org/10.1353/ils.2010.0003

Choi, Y. (2010), "Effects of contextual factors on image searching on the Web", Journal of the American Society for Information Science and Technology, 61(10), 2011-2028.

Choi, Y. (2013), "Analysis of image search queries on the web: Query modification patterns and semantic attributes", Journal of the American Society for Information Science and Technology, Vol. 64 No. 7, pp.1423-1441. https://doi.org/10.1002/asi.22831

Choi, Y., \& Hsieh-Yee, I. (2010), "Finding images in an online public access catalogue: Analysis of user queries", Canadian Journal of Information and Library Science, Vol. 34 No. 3, pp.271-295. https://doi.org/10.1353/ils.2010.0004

Choi, Y., \& Rasmussen, E. M. (2002), "Users' relevance criteria in image retrieval in American history", Information processing \& management, 38(5), 695-726.

Choi, Y., \& Rasmussen, E. M. (2003), "Searching for images: The analysis of users' queries for image retrieval in American history", Journal of the American Society for Information Science and Technology, Vol. 54 No. 6, pp.498-511. https://doi.org/10.1002/asi.10237

Chu, H. (2001), "Research in image indexing and retrieval as reflected in the literature", Journal of the American Society for Information Science and Technology, 52(12), 1011-1018.

Chu, H. (2015), "Research methods in library and information science: A content analysis", Library and Information Science Research, 37, 36-41.

Chung, E., \& Yoon, J. (2011), "Image needs in the context of image use: An exploratory study", Journal of Information Science, Vol. 37 No. 2, pp.163-177. https://doi.org/10.1177/0165551511400951 
Cunningham, S. J., Bainbridge, D., \& Masoodian, M. (2004), "How people describe their image information needs: A grounded theory analysis of visual arts queries", In Proceedings of the 2004 Joint ACM/IEEE Conference on Digital Libraries, Tuscon, AZ, USA, pp. 4748.

Conniss, L., Ashford, A. J., \& Grapham, M. E. (2002), "Information seeking behaviour in image retrieval: VISOR I final report”, Art Libraries Journal, Vol. 27 No. 2, pp.46-47. https://doi.org/10.1017/S0307472200012736

De-Arteaga, M., Eggel, I., Do, B., Rubin, D., Kahn, C. E., \& Müller, H. (2015), “Comparing image search behaviour in the ARRS GoldMiner search engine and a clinical PACS/RIS”, Journal of Biomedical Informatics, Vol. 56, pp.57-64. https://doi.org/10.1016/j.jbi.2015.04.013

Deng, S., Zhao, A., Huang, R., \& Zhao, H. (2019), "Image needs on social Q\&A sites: a comparison of Zhihu and Baidu Zhidao", The Electronic Library.

Enser, P. (2000), "Visual image retrieval: seeking the alliance of concept-based and contentbased paradigms", Journal of Information Science, 26(4), 199-210.

Enser, P. G., Sandom, C. J., Hare, J. S., \& Lewis, P. H. (2007), "Facing the reality of semantic image retrieval", Journal of documentation.

Ercegovac, Z. (2012), "Digital Image Tagging: A Case Study with Seventh Grade Students", School Libraries Worldwide, 18(1).

Forsyth, D. A. (1999), "Computer vision tools for finding images and video sequences", Library Trends, Vol. 48 No. 2, pp.326-355.

Fry, E. (1998), "Image access and cyber searching: The Philadelphia experiment", Art Documentation: Journal of the Art Libraries Society of North America, 17(2), 51-52.

Fukumoto, T., \& Akahori, K. (2002), “An analysis of image retrieval behavior for metadata type image database", Proceedings of the International Conference on Computers in

Education, 2002, Auckland, New Zealand, pp.1470-1471. https://doi.org/10.1109/CIE.2002.1186301

Gabridge, T., Gaskell, M., \& Stout, A. (2008), 'Information seeking through students' eyes: The MIT photo diary study", College \& Research Libraries, Vol. 69 No. 6, pp.510-523. https://doi.org/10.5860/crl.69.6.510

Given, L. M., Ruecker, S., Simpson, H., Sadler, E., \& Ruskin, A. (2007), "Inclusive interface design for seniors: Image-browsing for a health information context", Journal of the American Society for Information Science and Technology, Vol. 58 No. 11, pp.16101617. https://doi.org/10.1002/asi.20645

Göker, A., Butterworth, R., MacFarlane, A., Ahmed, T. S., \& Stumpf, S. (2016), "Expeditions through image jungles: the commercial use of image libraries in an online environment", Journal of Documentation.

Goodrum, A. A. (2005), "I can't tell you what I want, but I'll know it when I see it: Terminological disconnects in digital image reference", Reference \& User Services Quarterly, 46-53.

Graham, M. E., \& Bailey, C. (2006), "Digital images and art historians-Compare and contrast revisited", Art libraries journal, 31(3), 21-24.

Hastings, S. K. (1999), "Evaluation of image retrieval systems: Role of user feedback", Library Trends, Vol. 48 No. 2, pp.438-452.

Hepburn, P., \& Fiscella, J. B. (2006), "Constructing descriptive records for an art image database: What do use statistics tell us?", College \& research libraries, 67(4), 334-353. 
Hollink, V., Tsikrika, T., \& de Vries, A. P. (2011), "Semantic search log analysis: A method and a study on professional image search", Journal of the American Society for Information Science and Technology, Vol. 94 No. 4, pp.691-713. https://doi.org/10.1002/asi.21484

Huang, K., \& Kelly, D. (2013), "The daily image information needs and seeking behavior of Chinese undergraduate students", College \& Research Libraries, Vol. 74 No. 3, pp.243261. https://doi.org/10.5860/crl-331

Hung, T. Y. (2005), "Search moves and tactics for image retrieval in the field of journalism: A pilot study", Journal of Educational Media \& Library Sciences, Vol. 42 No. 3, pp.329346.

Jansen, B. J. (2008), "Searching for digital images on the web", Journal of Documentation, Vol. 64 No. 1, pp.81-101. https://doi.org/10.1108/00220410810844169

Jörgensen, C., Stvilia, B., \& Wu, S. (2014), "Assessing the relationships among tag syntax, semantics, and perceived usefulness", Journal of the Association for Information Science and Technology, 65(4), 836-849.

Konkova, E., MacFarlane, A., \& Göker, A. (2016), “Analysing creative image search information needs", Knowledge Organization, Vol. 43 No. 1, pp.13-21. https://doi.org/10.5771/0943-7444-2016-1-13

Lee, H. J., \& Neal, D. (2010), “A new model for semantic photograph description combining basic levels and user-assigned descriptors", Journal of Information Science, 36(5), 547565.

Lee, P. \& Stewart, D. (2016), Photo sharing: trillions and rising. https://www2.deloitte.com/content/dam/Deloitte/global/Documents/Technology-MediaTelecommunications/gx-tmt-prediction-online-photo-sharing.pdf

Lundh, A., \& Alexandersson, M. (2012), "Collecting and compiling: The activity of seeking pictures in primary school”, Journal of Documentation, Vol. 68 No. 2, pp.238-253. https://doi.org/10.1108/00220411211209212

Matusiak, K.K. (2006), "Information seeking behavior in digital image collections: A cognitive approach", The Journal of Academic Librarianship, Vol. 32 No. 5, pp.479-488. https://doi.org/10.1016/j.acalib.2006.05.009

Matusiak, K.K. (2017), "Studying information behavior of image users: An overview of research methodology in LIS literature, 2004-2015", Library \& Information Science Research, Vol. 39 No. 1, pp.53-60. https://doi.org/10.1016/j.lisr.2017.01.008.

Matusiak, K. K., Harper, A., \& Heinbach, C. (2019a), "Use and reuse of visual resources in student papers and presentations", The Electronic Library.

Matusiak, K.K., Heinback, C., Harper, A., \& Bovee, M. (2019b), "Visual literacy in practice: Use of images in students' academic work", College \& Research Libraries, Vol. 80 No. 1, pp.123-139. https://doi.org/10.5860/crl.80.1.123

Matusiak, K.K. (2013), "Image and multimedia resources in an academic environment: A qualitative study of students' experiences and literacy practices", Journal of the American Society for Information Science and Technology, Vol. 64 No.8, pp.1577-1589. https://doi.org/10.1002/asi.22870

McBride, C. (2006), "Curators and their use of digital images", Art Libraries Journal, 31(3), 25 31.

Ménard, E. (2011), "Search behaviours of image users: A pilot study on museum objects", Partnership: The Canadian Journal of Library and Information Practice and Research, Vol. 6 No. 1. https://doi.org/10.21083/partnership.v6il.1433 
Ménard, E., \& Khashman, N. (2014), "Image retrieval behaviours: Users are leading the way to a new bilingual search interface”, Library Hi Tech, Vol. 32 No. 1, pp.50-68. https://doi.org/10.1108/LHT-06-2013-0067

Merriam, S. B., \& Tisdell, E. J. (2015), Qualitative research: A guide to design and implementation (4th ed.). John Wiley \& Sons.

Neal, D. M. (2010), "Emotion-based tags in photographic documents: The interplay of text, image, and social influence/Les étiquettes basées sur des émotions dans les documents photographiques: l'interaction entre le texte, l'image et l'influence sociale", Canadian Journal of Information and Library Science, 34(3), 329-353.

Okoli, C., \& Schabram, K. (2010), "A guide to conducting a systematic literature review of information systems research", SSRN Electronic Journal. https://doi.org/10.2139/ssrn.1954824

Petrelli, D., \& Clough, P. (2012), “Analysing user's queries for cross-language image retrieval from digital library collections", The Electronic Library, Vol. 30 No. 2, pp.197-219. https://doi.org/10.1108/02640471211221331

Pisciotta, H. A., Dooris, M. J., Frost, J., \& Halm, M. (2005), "Penn State's visual image user study", portal: Libraries and the Academy, 5(1), 33-58.

$\mathrm{Pu}, \mathrm{H}$. T. (2008), “An analysis of failed queries for web image retrieval", Journal of Information Science, 34(3), 275-289.

Rampton, J. (2015, April 22), "Crowdsourcing your images: 4 powerful sites to connect directly with your audience", Forbes.

https://www.forbes.com/sites/johnrampton/2015/04/22/crowdsourcing-your-images-4powerful-sites-to-connect-directly-with-your-audience/\#3b6d0e546e 74

Schlosser, K. (2018, September 17), Getty Images' visual assets will enhance Alexa searches on Amazon's Echo devices with a screen. GeekWire. https:/www.geekwire.com/2018/gettyimages-visual-assets-will-enhance-alexa-searches-amazons-echo-devices-screen/

Sedghi, S., Sanderson, M., \& Clough, P. (2011, November), "Medical image resources used by health care professionals", In aslib proceedings. Emerald Group Publishing Limited.

Sedghi, S., Sanderson, M., \& Clough, P. (2013), "How do healthcare professionals select the medical images they need?", In Aslib Proceedings. Emerald Group Publishing Limited.

Shankar, S., O’Brien, H. L., \& Absar, R. (2018), "Rhythms of everyday life in mobile information seeking: Reflections on a photo-diary study", Library Trends, Vol. 66 No. 4, pp.535-567. https://doi.org/10.1353/lib.2018.0016

Simor, S. (2003), "Visual art resources online: Issues, trends and challenges", Art Documentation: Journal of the Art Libraries Society of North America, 22(1), 33-40.

Simpson, J. (2017, August 25), "Finding brand success in the digital world", Forbes. https://www.forbes.com/sites/forbesagencycouncil/2017/08/25/finding-brand-success-inthe-digital-world/\#26546a91626e

Stvilia, B., \& Jörgensen, C. (2010), "Member activities and quality of tags in a collection of historical photographs in Flickr", Journal of the American Society for Information Science and Technology, 61(12), 2477-2489.

Treat, L., \& Judkins, J. (2018), "First there is the creative decision, then there is the dollar decision': Information-seeking behaviors of filmmakers using moving image archives", The American Archivist, Vol. 81 No. 2, pp.373-393. https://doi.org/10.17723/0360-908181.2.373 
Tsikrika, T., Müller, H., \& Kahn Jr, C. E. (2012), "Log analysis to understand medical professionals' image searching behaviour", Proceedings of the 24th European Medical Informatics Conference, 2012.

Wang, X., Erdelez, S., Allen, C., Anderson, B., Cao, H., \& Shyu, C. R. (2012), "Role of domain knowledge in developing user-centered medical-image indexing", Journal of the American Society for Information Science and Technology, 63(2), 225-241.

Woll, J. (2005), "User Access to Digital Image Collections of Cultural Heritage Materials: The Thesaurus as Pass-Key", Art Documentation: Journal of the Art Libraries Society of North America, 24(2), 19-28.

Wu, C.-Y., Lin, L.-J. C., \& Tseng, Y.-H. (2004), “The use of QBIC content-based image retrieval system," Journal of Library and Information Studies, Vol. 1 No. 4, pp.21-35.

Yoon, J. (2010), "Utilizing quantitative users' reactions to represent affective meanings of an image", Journal of the American Society for Information Science and Technology, 61(7), 1345-1359.

Yoon, J. (2011), "Searching images in daily life", Library \& Information Science Research, Vol. 33 No. 4, pp.269-275. https://doi.org/10.1016/j.lisr.2011.02.003

Yoon, J., \& Chung, E. (2011), "Understanding image needs in daily life by analyzing questions in a social Q\&A site", Journal of the American Society for Information Science and Technology, Vol. 62 No. 11, 2201-2213. https://doi.org/10.1002/asi.21637 